\title{
Prevalence and cumulative incidence of abnormal cervical cytology among HIV-infected Thai women: a 5.5-year retrospective cohort study
}

\author{
Amphan Chalermchockcharoenkit ${ }^{1 *}$, Chenchit Chayachinda', Manopchai Thamkhantho', Chulaluk Komoltri
}

\begin{abstract}
Background: Cervical cancer is one of the most common AIDS-related malignancies in Thailand. To prevent cervical cancer, The US Public Health Service and The Infectious Disease Society of America have recommended that all HIV-infected women should obtain 2 Pap smears 6 months apart after the initial HIV diagnosis and, if results of both are normal, should undergo annual cytological screening. However, there has been no evidence in supporting whether this guideline is appropriate in all settings - especially in areas where HIV-infected women are living in resource-constrained condition.

Methods: To determine the appropriate interval of Pap smear screenings for HIV-infected Thai women and risk factors for subsequent abnormal cervical cytology, we assessed the prevalence, cumulative incidence and associated factors of cervical cell abnormalities (atypical squamous cell of undetermined significance or higher grades, ASCUS+) among this group of patients.
\end{abstract}

Results: The prevalence of ASCUS+ was $15.4 \%$ at the first visit, and the cumulative incidence of ASCUS+ gradually increased to $37 \%$ in the first 3.5 years of follow-up appointments (first 7 times), and tended to plateau in the last 2 years. For multivariate correlation analysis, women with a CD4 count $<350$ cells/ $\mu \mathrm{L}$ had a significant correlation with ASCUS+ $(P=0.043)$. There were no associations of subsequent ASCUS+ with age, pregnancy, contraceptive method, highly active anti-retroviral treatment, assumed duration of infection, or the CD4 count nadir level.

Conclusion: There are high prevalence and cumulative incidence of ASCUS+ in HIV-infected Thai women. With a high lost-to-follow-up rate, an appropriate interval of Pap smear screening cannot be concluded from the present study. Nevertheless, the HIV-infected Thai women may require more than two normal semi-annual Pap smears before shifting to routinely annual cytologic screening.

\section{Background}

Thailand is one of the world's endemic areas for HIV infection. In 2007, approximately 250,000 women were living with HIV infection [1]. Women living with HIVAIDS clearly have an increased risk of cervical cancer. A recent study in HIV-infected women in Thailand found that cervical cancer was the most common AIDS-related malignancy[2]. Sufficient Papanicolaou (Pap) smear screening would render a high yield in early detection because of its affordability, availability and accessibility. Cervical squamous cell abnormalities in HIV-infected

\footnotetext{
* Correspondence: siacl@mahidol.ac.th

'Department of Obstetrics and Gynaecology, Faculty of Medicine Siriraj

Hospital, Mahidol University, Thailand

Full list of author information is available at the end of the article
}

women, compared with women who are not infected, progress more rapidly to more significant cervical intraepithelial neoplasia (CIN) or even invasive cervical cancer[3].

Our previous study indicated that $13.3 \%$ of HIV-infected pregnant women had cervical squamous cell abnormalities [4], while the prevalence of abnormal Pap smears from many studies seemed to be higher (20\%-40\%)[5-8]. However, there are different backgrounds. Many studies reported that cytology was primarily subject to false negative results[3,7,9-12]. Even with a negative for intraepithelial lesion (NIL) with an initial Pap smear, $20 \%$ of HIV-infected women will be later found with biopsy-confirmed cervical squamous cell intraepithelial lesions (SILs) in 3 years[3]. This may either reflect an incident lesion or

\section{() Biomed Central}


reflect a prevalent lesion missed on Pap smear. Moreover, a study aimed at evaluating the sensitivity and specificity of Pap smears showed that $38 \%$ of all CIN would have been missed if routine colposcopy and biopsy had not been performed[7].

HIV treatment guidelines issued by The US Public Health Service and The Infectious Disease Society of America have recommended that all HIV-infected women should obtain two Pap smears 6 months apart after an initial HIV diagnosis and, if the results of both are normal, these women should then undergo annual cytologic screening[13]. However, the guideline has not been revised since 1995 and there has been no evidence to support that this guideline is appropriate in all settings, especially for HIV-infected women living in resource-constrained conditions where long-term studies are difficult to conduct. Moreover, currently no national cervical screening guidelines are in use in Thailand.

For these reasons, semi-annual Pap smear screenings for all HIV-infected Thai women, (not only women with CD +4 counts $<200$ cells $/ \mu \mathrm{L}$ ), development of health education and improved efforts to increase the trust between health care providers and women, have been implemented in our clinic since 2004. The present study aimed to determine an appropriate strategy for Pap smear screening and risk factors related to subsequent abnormal cervical cytology. Prevalence, cumulative incidence and associated factors of cervical cell abnormalities (atypical squamous cell of undetermined significance; ASCUS or higher grades, i.e. atypical squamous cells cannot exclude high grade squamous intraepithelial lesion; ASC-H, low grade squamous intraepithelial lesion; LSIL, High grade squamous intraepithelial lesion; HSIL, squamous cell carcinoma) designated as ASCUS+ among this group of patients were assessed.

\section{Methods}

With the program implementation of semi-annual Pap smear screening for all HIV-infected women at the Female Sexually Transmitted Disease Clinic (STD Clinic), Faculty of Medicine Siriraj Hospital, Mahidol University from January 2004 to December 2009, the STD-medical records of $901 \mathrm{HIV}$-infected women were available for review to search for the results from first Pap smears. In our clinical protocol, all HIV-infected women were counselled to receive baseline Pap smear screening, and were required to come back for the next screening every 6 months. Sociodemographic data were collected using a structured medical record form. Blood sample for CD4+ count was obtained every 6 months. The result was determined in a local laboratory conducted by the Department of Microbiology in our hospital.
After a clinical and pelvic examination, women with signs of STDs were counselled and treated, and asked to return to the clinic 2 weeks later for baseline Pap smear screening. All Pap smear specimens were obtained by gynaecologists from the endocervix, cervical transformation zone and discharge at posterior fornix of vagina using a cotton tip stick and Ayre spatula, as described in the VCE technique. Cytological analyses were undertaken at the Division of Cytology of Department of Obstetrics and Gynaecology, Faculty of Medicine Siriraj Hospital. All Pap smear tests were processed and read by our certified senior cytotechnologists based on the 2001 Bethesda system guideline[14]. According to our policy, colposcopy must be offered in all cases of ASCUS+, but due to the occurrence of lost to followup, some of them were not able to have colposcopy. If indicated by colposcopy or cytology results, lesions were further evaluated by biopsy, endocervical curettage, or loop electrical excision. Definite surgical treatment (hysterectomy) was provided as indicated[15].

Participants who initially had NIL and came for their second Pap smear screening were included in the subgroup analysis to assess the cumulative incidence and factors associated with ASCUS+: namely age, parity, abortion, contraceptive methods, antiretroviral treatment, assumed duration HIV infection, CD4 count nadir and baseline CD4 count. All women with subsequent ASCUS/LSIL were not repeatedly enrolled among the rest of the study population. The assumed duration HIV infection was the duration that was estimated by the patient after counseling and the CD4 count nadir was the lowest CD4 count recorded. Data entry and analysis was performed by SPSS version 13 (SPSS, Chicago, IL, USA). Data were presented as frequency, percentage, mean \pm standard deviation (SD), or median with ranges as appropriate. The cumulative incidence of ASCUS + was estimated over the course of this study using standard life table methods. The student's $t$-test was used to compare means and Pearson $X^{2}$-test or Fisher's exact test was used to compare proportions between HIV-infected women with ASCUS+ and NIL at first Pap smear, and between HIV-infected women with subsequent ASCUS+ and NIL who had a NIL at first Pap smear. Statistically significant differences were defined as $p<0.05$. The Mann Whitney $U$ test was used for variables that were not normally distributed. Multivariate correlation analysis was used to adjust for potential confounding factors. The study was conducted in accordant with the ethics principle of declaration of Helsinki, and the study protocol was approved by the Siriraj Institutional Review Board.

\section{Results}

Of 901 HIV-infected women, 80 women were excluded as 18 women did not received Pap smear screening, 12 
women did not have an intact cervix at baseline, 31 women had a previous diagnosis or treatment of cervical intraepithelial neoplasia, and 19 women had no documentation of CD4+ count. As a result, 821 women were included in the analysis. The study population had a mean age of 30.1 years (range 14 - 65), a median baseline CD4 count of 324 cells/ $\mu \mathrm{L}$ (range 2 - 999) and a median CD4 count nadir of 206 cells/ $\mu \mathrm{L}$ (range 2 - 930).

Of the 821 women, 237 women $(28.9 \%)$ had CD4 counts less than 200 cells/ $\mu \mathrm{L}$ and 395 women (48.1\%) were receiving highly active antiretroviral therapy (HAART). There were 443 women who initially came to the clinic for antenatal care (ANC), 43 women for postpartum Pap smear screening, 37 women with STD related problems or positive pre-operative gynaecologic anti-HIV screening, and 298 women referred from the HIV clinic, Department of Preventive Medicine, for Pap smear screenings. The Pap smear screening data were from the women's first 12 semi-annual visits (over a period of 5.5 years) and consisted of 2,852 Pap smear tests.

\section{Prevalence of ASCUS+}

The prevalence of cervical squamous cell abnormalities from 821 initial Pap smear screenings was $15.4 \%$, consisting of ASCUS 2.8\%, atypical squamous cells cannot exclude high grade squamous intraepithelial lesion (ASC-H) 0.6\%, LSIL 8.5\%, and HSIL 3.5\% (Table 1). The most common coincident genital infection was fungal infection at $19.4 \%$ of the women. Compared with women with NIL, those with ASCUS+ had significantly higher proportions of receiving HAART and the baseline CD4

\begin{tabular}{lcc}
$\begin{array}{l}\text { Table } 1 \text { Frequency of cervical cytological findings at the } \\
\text { first visit }\end{array}$ & $\begin{array}{c}\text { Frequency } \\
\text { (cases) }\end{array}$ & Percent \\
\hline Cervical cytological findings & 412 & 50.2 \\
\hline $\begin{array}{l}\text { Negative for intraepithelial lesion } \\
\text { Without organism and inflammation }\end{array}$ & 159 & 19.4 \\
Candida and budding yeasts & 13 & 1.6 \\
Trichomonas vaginalis & 2 & 0.2 \\
Bacterial vaginosis & 12 & 1.5 \\
Herpes simplex virus & 96 & 11.7 \\
Reactive cellular changes associated with & & \\
inflammation & & 2.8 \\
Squamous cell abnormalities & 23 & 0.6 \\
ASCUS & 5 & 8.5 \\
ASC-H & 70 & 3.5 \\
LSIL & 29 & 100 \\
HSIL & 821 & \\
Total & &
\end{tabular}

ASCUS, atypical squamous cell of undetermined significance; ASC-H, atypical squamous cell cannot exclude HSIL; LSIL, low grade squamous intraepithelial lesion;

HSIL, high grade squamous intraepithelial lesion. count $<200$ cells $/ \mu \mathrm{L}$ (58.3\% vs. $46.3 \%, 37.8 \%$ vs. $28.2 \%$, respectively). A higher proportion of baseline CD4 count $<350$ cells $/ \mu \mathrm{L}$ was also found in women with ASCUS+ (66.9\% vs. $52.4 \%)$. In addition they had a significantly longer mean of assumed duration of HIV infection but a lower mean of CD4 count nadir $(7.1 \pm 4.1$ years vs. $5.9 \pm$ 3.4 years and $188.9 \pm 142.7$ cells $/ \mu \mathrm{L}$ vs. $239.9 \pm 182.8$ cells $/ \mu \mathrm{L}$, respectively) as shown in Table 2 .

\section{Cumulative incidence of ASCUS+}

Of the 444 women who had NIL at initial Pap smear screening and came for the second test, the cumulative incidence of ASCUS + was $15 \%$. The cumulative incidence was gradually increased in the first 7 visits to $37 \%$ and tended to plateau in the last 4 visits (Figure 1). There was a median follow-up time of 12 months when the first ASCUS+ was detected. The mean and median number of Pap smears per patient was 2.7 and 2.0, respectively. None of the patients got pregnant during the follow-up visits in this study. There was no statistical difference between development of ASCUS+ from NIL in terms of age, number of abortions, contraceptive methods, receiving HAART, assumed duration of HIV infection, or CD4 count nadir level. However, the proportion of multipara women and women with CD4 count $<200$ cells $/ \mu \mathrm{L}$ showed statistically significant differences between the two groups $(84.2 \%$ vs. $72.8 \%$, $p 0.022 ; 37.9 \%$ vs. $20.9 \%, p=0.016$, respectively). In addition the proportion of women with CD4 count $<350$ cells/ $\mu \mathrm{L}$ was still significantly higher $(62.1 \%$ vs. $48.4 \%$,

Table 2 Comparison of the baseline characteristics of women with ASCUS+ and NIL at first Pap smear

\begin{tabular}{|c|c|c|c|}
\hline & $\begin{array}{l}\text { ASCUS+ } \\
(N=127)\end{array}$ & $\begin{array}{c}\text { NIL } \\
(\mathrm{N}=694)\end{array}$ & $P$ \\
\hline Age (yrs) & $30.9 \pm 8.4$ & $29.8 \pm 7.1$ & 0.080 \\
\hline Gravidarum $\geq 1$ & $102(80.3)$ & $592(85.3)$ & 0.153 \\
\hline Parity $\geq 1$ & $93(73.2)$ & $526(75.8)$ & 0.537 \\
\hline Abortion $\geq 1$ & $37(29.1)$ & $226(32.6)$ & 0.446 \\
\hline \multicolumn{4}{|l|}{ Contraception } \\
\hline Tubal sterilization & $55(34.3)$ & $372(53.6)$ & 0.076 \\
\hline Condom & $50(39.4)$ & $237(34.1)$ & \\
\hline Others & $22(17.3)$ & 85 (12.2) & \\
\hline $\begin{array}{l}\text { Time since assumed infection } \\
\text { (yrs) }\end{array}$ & $7.1 \pm 4.1$ & $5.9 \pm 3.4$ & $0.001^{\#}$ \\
\hline Receiving HAART & $74(58.3)$ & $321(46.3)$ & 0.013 \\
\hline $\begin{array}{l}\text { Baseline CD4 count } \\
<350 \text { cells } / \mu \mathrm{L}\end{array}$ & $85(66.9)$ & $364(52.4)$ & 0.003 \\
\hline CD4 count nadir (cells/ $\mu \mathrm{L}$ ) & $\begin{array}{c}188.9 \pm \\
142.7\end{array}$ & $\begin{array}{l}239.9 \pm \\
182.8\end{array}$ & 0.000 \\
\hline
\end{tabular}

Data are mean \pm standard deviation or $\mathrm{n}(\%)$.

\# Mann-Whitney $U$ test.

ASCUS+, atypical squamous cell of undetermined significance or higher grades;

$\mathrm{NIL}$, negative for intraepithelial lesion; HAART, highly active antiretroviral therapy. 


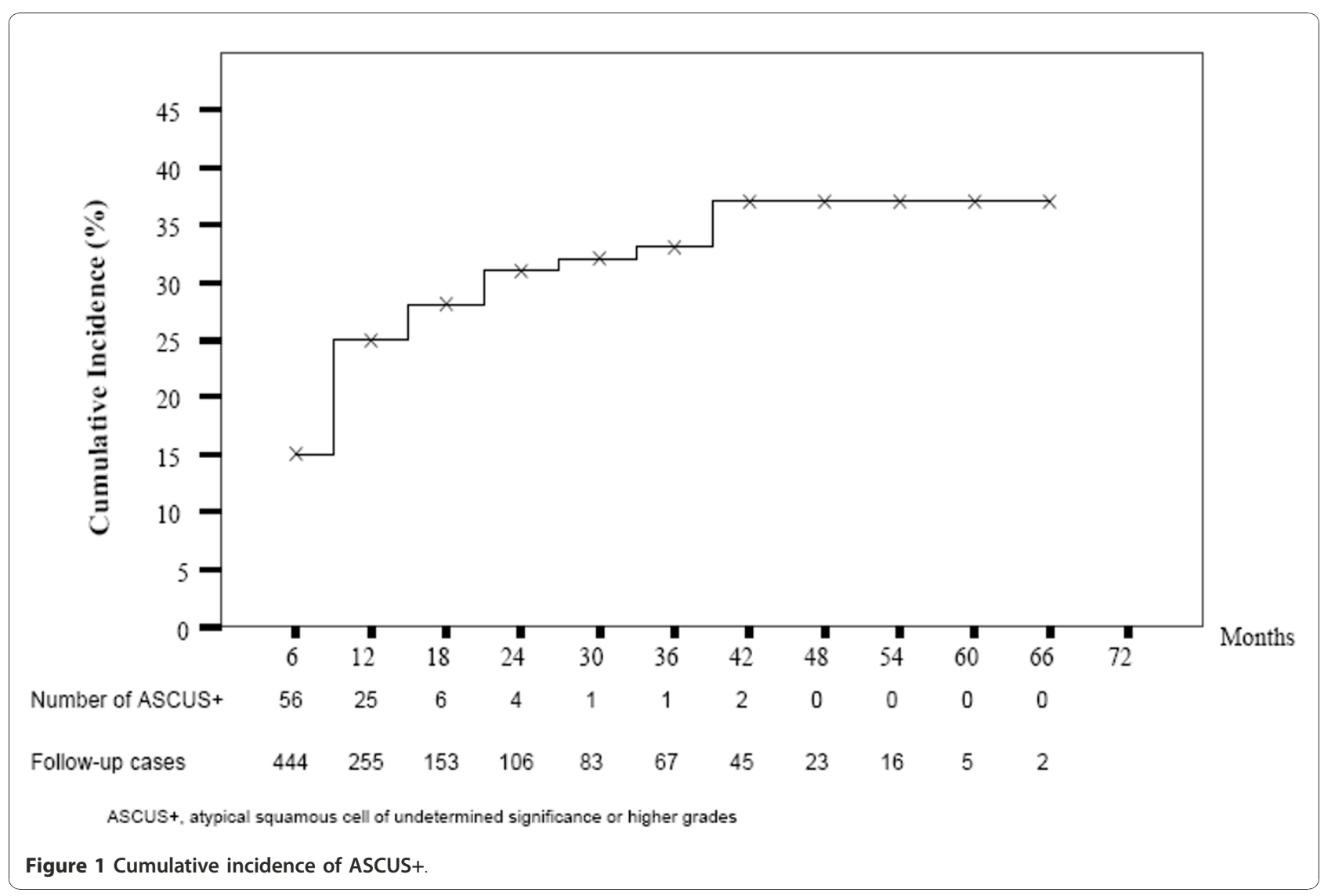

$p=0.018$ )(Table 3). By multivariate correlation analysis, adjusted for multiparity women and CD4 count $<350$ demonstrated that the CD4 count $<350$ cells $/ \mu \mathrm{L}$ was the only significant risk factor for developing subsequent ASCUS+ $(p=0.043)$.

\section{Colposcopic and histologic diagnosis of ASCUS+}

Of the 95 women with subsequent ASCUS+, 16 (16.8\%) had ASCUS, 1 (1.1\%) had ASC-H, 60 (63.2\%) had LSIL and 18 (18.9\%) had HSIL (data not shown). Seventy six women were able to undergo colposcopic investigation and 19 of them (25.0\%) were subsequently colposcopically-diagnosed CIN II-III (Table 4). Nineteen of twenty-four women who were colposcopically diagnosed CINII-III and/or cytologically diagnosed HSIL were able to undergo loop electrical excision procedure of cervix (LEEP) or cold knife conization at this hospital. There were histological assessments which confirmed CIN II-III in 12/19 (63\%) and invasive squamous carcinoma in $1 / 19$ (5.3\%).

\section{Discussion}

This is the first long-term retrospective cohort study of cervical squamous cell abnormalities in HIV-infected
Table 3 Comparison of the baseline characteristics of women with subsequent ASCUS+ and NIL who had a NIL at first Pap smear

\begin{tabular}{|c|c|c|c|}
\hline & $\begin{array}{l}\text { ASCUS+ } \\
(\mathrm{N}=95)\end{array}$ & $\begin{array}{c}\mathrm{NIL} \\
(\mathrm{N}=349)\end{array}$ & $P$ \\
\hline Age (yrs) & $30.0 \pm 8.7$ & $30.1 \pm 7.0$ & 0.901 \\
\hline Gravidarum $\geq 1$ & $85(89.5)$ & $299(85.7)$ & 0.337 \\
\hline Parity $\geq 1$ & $80(84.2)$ & $254(72.8)$ & 0.022 \\
\hline Abortion $\geq 1$ & $23(24.2)$ & $115(33.0)$ & 0.103 \\
\hline \multicolumn{4}{|l|}{ Contraception } \\
\hline Tubal sterilization & $60(63.2)$ & $198(56.7)$ & 0.187 \\
\hline Condom only & $28(29.5)$ & $101(28.9)$ & \\
\hline Others & $7(7.4)$ & $50(14.3)$ & \\
\hline $\begin{array}{l}\text { Time since assumed infection } \\
\text { (yrs) }\end{array}$ & $6.1 \pm 2.7$ & $5.9 \pm 3.0$ & $0.661^{\#}$ \\
\hline Receiving HAART & $52(54.7)$ & $160(45.8)$ & 0.124 \\
\hline $\begin{array}{l}\text { Baseline CD4 count } \\
<350 \text { cells } / \mu \mathrm{L}\end{array}$ & $59(62.1)$ & $169(48.4)$ & 0.018 \\
\hline CD4 count nadir (cells/ $\mu \mathrm{L}$ ) & $\begin{array}{c}206.3 \pm \\
149.4\end{array}$ & $\begin{array}{c}244.9 \pm \\
189.1\end{array}$ & $0.067^{\#}$ \\
\hline
\end{tabular}

Data are mean \pm standard deviation or $\mathrm{n}(\%)$. \# Mann-Whitney U test.

HAART, highly active antiretroviral therapy; ASCUS+, atypical squamous cell of undetermined significance or higher grades; NIL, negative for intraepithelial lesion. 
Table 4 Colposcopic results in women with abnormal Pap smears

\begin{tabular}{lcccc}
\hline & & \multicolumn{3}{c}{ Colposcopic results $\mathbf{n}(\%)$} \\
\cline { 3 - 5 } Abmornal Pap smears & $\mathbf{N}$ & Normal & HPV/CIN I & CIN II-III \\
\hline ASCUS & 14 & $4(28.6)$ & $9(64.3)$ & $1(7.1)$ \\
LSIL & 46 & $3(6.5)$ & $36(78.3)$ & $7(15.2)$ \\
HSIL & 16 & 0 & $5(31.3)$ & $11(68.7)$ \\
Total & 76 & $7(9.2)$ & $50(65.8)$ & $19(25.0)$ \\
\hline
\end{tabular}

ASCUS, atypical squamous cell of undetermined significance

LSIL, low grade squamous intraepithelial lesion

HSIL, high grade squamous intraepithelial lesion

HPV, human papilloma virus

CIN I, cervical intraepithelial neoplasia I

CINII-III, cervical intraepithelial neoplasia II-III

Thai women. It is well recognized that women with HIV infections have a higher prevalence, incidence, persistence, and progression of squamous intraepithelial lesions as compared with those without the infection. The prevalence of cervical squamous cell abnormalities and SILs in the present study was similar to that in our previous study[4]. Compared with several previous studies[5-8], the result of Pap smear screenings from the present study showed a slightly lower prevalence $(15.4 \%$ vs.20\%-40\%). In addition to the different backgrounds, this may be due to the fact that the majority of participants in this study were either ante-partum, or immediate postpartum.

Interestingly, the cumulative incidence of ASCUS+ in the present study gradually increased to $37 \%$ in the first 3.5 years of follow-up appointments (first 7 times) and tended to plateau in the last 2 years. In addition, one woman with cytological diagnosis of HSIL and with a histologic diagnosis of CINIII was diagnosed from the Pap smear at her seventh follow-up appointment. Comparable with this study, a previous study found that among HIV - infected women whose initial Pap smear was negative for intraepithelial lesion (NIL), about 20\%$35 \%$ of them would develop cytologic abnormalities over 3.0-5.5 years[3]. This supports the fact that there is a high rate of false negative Pap smear results among HIV-infected patients, as mentioned in a previous study [16]. The findings prompted us to reconsider the appropriate interval of Pap smear screenings for HIV-infected women as recommended by The US Public Health Service and The Infectious Disease Society of America in our setting. Our population might require more than two normal semi-annual Pap smear before shifting to annual cytologic screening. As the present study had high drop-out rate in the first 2 years, we believe that the real incidence of ASCUS+ might be higher. Previous studies have base analysis on less frequent Pap smears than ours; some of them did not pay sufficient attention to the lag period which is supposed to play an important part in cervical carcinogenesis.
Many studies demonstrated that women with a CD4 count $<200$ cells $/ \mu \mathrm{L}$ were at particular risk of cervical cell abnormalities[4,16-19]. This means that immunological status also plays a crucial part in cervical carcinogenesis. We found that the women with ASCUS+ had significantly higher proportions of receiving HAART than those with NIL. This is the most likely reflection that these women had an underlying poor immune status by their own merit without any correlation of HAART. The CD4 count cut-off point that we used to predict cumulative incidence of ASCUS+ was 350 cells/ $\mu \mathrm{L}$, which is compatible with a study from Brazil[19]. Recently, the Thai Ministry of Public Health initiates HAART for all HIV-infected patients who have CD4 counts at this level or lower. The CD4 counts $<200$ cells $/ \mu \mathrm{L}$ seem to be far too low to detect new ASCUS+ cases and may be too low for basing a decision to initiate HAART regimen. However, we did not look at the change of CD4 count and its impact on cumulative incidence of ASCUS+.

A well-designed study demonstrated that the incidence of SILs increased with time, especially the ones with lower CD4 count and oncogenic HPV infection [17]. In addition, a study from Italy with 132 HIVinfected women who had invasive cervical cancer (ICC) showed that the interval between the first HIV-positive test and invasive cancer diagnosis was longer than 10 years in almost half of the women[20]. We also found that the assumed duration of HIV infection and the CD4 count nadir level were associated with a high prevalence of ASCUS+ from the initial Pap smear. However, they were not associated with the cumulative incidence of ASCUS+.

In the present study only $0.1 \%(1 / 821)$ of HIV-infected women had invasive squamous cell carcinoma. This woman had a baseline CD 4 count of 148 cells/ $\mu \mathrm{L}$ and had a 14-year duration assumed HIV infection. She had a cytologic HSIL at the third Pap smear and colposcopic diagnosis of HSIL. With a lower incidence of invasive squamous cell carcinoma, our study may not represent the whole picture of HIV-infected women in Thailand since the incidence in this study was lower than the figure reported from a previous study conducted in Thailand[21]. A high number of women were already on HAART at commencement of the study. HAART might have beneficially protective on preventing cervical carcinogenesis[22,23]. More important reasons were the early detection by a regular semi-annual check-up, the development of health education, and the growth of trust between health care providers and patients. Smoking was not included in the baseline characteristics because almost all Thai women were not current or ex-smokers.

Several studies are currently investigating the benefits of adding HPV DNA tests to improve screening for 
cervical lesions and cancer - as screening for oncogenic HPV types is a more sensitive predictor of high grade squamous intra-epithelial lesions. Overall, the HPV test had a higher sensitivity among HIV-infected women as compared with HIV-uninfected women. One study in Thailand reported that the prevalence of high risk HPV infection in Thai HIV-seropositive women was 38.6\% [21], which was lower than that found in American (83.2\%) and Brazilian women (44.5\%)[24,25]. However, HPV DNA testing is not a routine screening test in this clinic due to its high cost. In addition, the specificity for cervical lesions of the test was low in HIV-infected women, resulting largely from a very high prevalence of HPV infection in women without cervical lesions. Thus, a HPV test may not provide benefits for cervical surveillance in the setting of HIV, because of its low specificity and poor predictive value[26,27].

In 1999, Holcomp, et al. demonstrated the significance of ASCUS in HIV-infected women by comparing cytological and histological results[28]. They found that $32 \%$ of ASCUS had histological cervical intraepithelial neoplasia (CIN). As a result, they suggested that early colposcopy should be considered in HIV infected women with ASCUS. There were a total of 16 women with ASCUS in our study, 14 were able to undergo colposcopy and 10 had colposcopic diagnosis of SILs (9 women with HPV/CIN I and 1 woman with CIN II-III) (Table 4). Although our study demonstrated that there was a high incidence of colposcopic diagnosis of SILs in women with ASCUS, only one woman in this group had colposcopic diagnosis of CIN II-III which had to be confirmed by tissue diagnosis. Since most of them had colposcopic diagnosis of HPV/CIN I and had a low socioeconomic background, it was unlikely that biopsies with pathological reports in these cases could be met.

There were a number of limitations in the present study that warranted mentioning. (1) The primary outcome was mainly the surrogate outcome of cervical cancer. Even though the incidence of abnormal lesions was high, these were mainly low grade lesions which could be regression, especially in younger women[29]. (2) False negative Pap smear was not included in the scope of the present study and this might have impact the findings as a previous study found a high false negative Pap smear rate in HIV-infected women with CD4 count $<500$ cells $/ \mu L[16]$. (3) The lack of viral load, colposcopy with tissue biopsy could not be performed in all cases; instead, a 'see and treat' technique was applied in order to decrease costs. (4) Due to the government universal coverage program and limited seats at Siriraj Hospital, many participants, especially a number in our study who were either ante-partum, or immediate post partum, were required to follow-up at their registered hospitals causing 250 women to be lost to follow up by the 6 month visit (36\%) and a further 133 (20\%) lost at 12 months. This is a loss of over $50 \%$ of study participants in the first year of follow-up. In addition, an effort to try to establish some relationship between health care providers and HIV - infected women was very difficult because of stigmatization of HIV. As a consequence, the rate of follow-up was quite low leading to the potential biases, such as survivorship bias/retention in care. In addition, other AIDS-indicated conditions and established risk factors of cervical cancer were not accounted for and there was one patient who died from an opportunistic infection during the follow-up period.

\section{Conclusions}

There are high prevalence and cumulative incidence of ASCUS + in HIV-infected Thai women. With a high lost-to-follow-up rate, an appropriate interval of Pap smear screening cannot be concluded from the present study. Nevertheless, the HIV-infected Thai women may require more than two normal semi-annual Pap smears before shifting to routinely annual cytologic screening.

\section{Acknowledgements}

This study was financially supported by a Grant from Faculty of Medicine Siriraj Hospital, Mahidol University. The authors deeply appreciate the contribution of all the staff nurses at the Female STD Clinic, Department of Obstetrics and Gynaecology, Siriraj Hospital, Mahidol University for their dedicated work.

\section{Author details}

${ }^{1}$ Department of Obstetrics and Gynaecology, Faculty of Medicine Siriraj Hospital, Mahidol University, Thailand. 'Division of Clinical Epidemiology, Faculty of Medicine Siriraj Hospital, Mahidol University, Thailand.

\section{Authors' contributions}

$A C$ and CC took initiative in developing the research project, and drafted the manuscript. AC participated in the design of the study. AC and CK participated in the data analysis. AC, CC and MT participated in the writing of the manuscript. All authors read and approved the final manuscript.

\section{Competing interests}

The authors declare that they have no competing interests.

Received: 30 June 2010 Accepted: 7 January 2011

Published: 7 January 2011

\section{References}

1. Epidemiological Fact Sheet on HIV and AIDS: Core data on epidemiology and response; Thailand 2008 update. [http://www.who.int/ hiv/pub/epidemiology/pubfacts/en/].

2. Kiertiburanakul S, Likhitpongwit S, Ratanasiri S, Sungkanuparph S: Malignancies in HIV-infected Thai patients. HIV Med 2007, 8(5):322-3.

3. Ellerbrock TV, Chiasson MA, Bush TJ, Sun XW, Sawo D, Brudney K, Wright TC: Incidence of cervical squamous intraepithelial lesions in HIVinfected women. JAMA 2000, 283(8):1031-7.

4. Chalermchockcharoenkit A, Sirimai K, Chaisilwattana P: High prevalence of cervical squamous cell abnormalities among HIV-infected women with immunological AIDS-defining illnesses. J Obstet Gynaecol Res 2006, 32(3):324-9.

5. Minkoff HL, Eisenberger-Matityahu D, Feldman J, Burk R, Clarke L: Prevalence and incidence of gynecologic disorders among women infected with human immunodeficiency virus. Am J Obstet Gynecol 1999, 180(4):824-36. 
6. Wright TC, Ellerbrock TV, Chiasson MA, Van Devanter N, Sun XW: Cervical intraepithelial neoplasia in women infected with human immunodeficiency virus: prevalence, risk factors, and validity of Papanicolaou smears. New York Cervical Disease Study. Obstet Gynecol 1994, 84(4):591-7.

7. Maiman M, Fruchter RG, Sedlis A, Feldman J, Chen P, Burk RD, Minkoff H: Prevalence, risk factors, and accuracy of cytologic screening for cervica intraepithelial neoplasia in women with the human immunodeficiency virus. Gynecol Oncol 1998, 68(3):233-9.

8. Massad LS, Riester KA, Anastos KM, Fruchter RG, Palefsky JM, Burk RD, Buren D, Greenblatt RM, Muderspach LI, Miotti P: Prevalence and predictors of squamous cell abnormalities in Papanicolaou smears from women infected with HIV-1. Women's Interagency HIV Study Group. J Acquir Immune Defic Syndr 1999, 21(1):33-41.

9. Kulasingam SL, Hughes JP, Kiviat NB, Mao C, Weiss NS, Kuypers JM, Koutsky LA: Evaluation of human papillomavirus testing in primary screening for cervical abnormalities: comparison of sensitivity, specificity, and frequency of referral. JAMA 2002, 288(14):1749-57.

10. Ratnam S, Franco EL, Ferenczy A: Human papillomavirus testing for primary screening of cervical cancer precursors. Cancer Epidemiol Biomarkers Prev 2000, 9(9):945-51.

11. Schneider A, Hoyer H, Lotz B, Leistritza S, Kuhne-Heid R, Nindl I, Muller B, Haerting J, Durst M: Screening for high-grade cervical intra-epithelial neoplasia and cancer by testing for high-risk HPV, routine cytology or colposcopy. Int J Cancer 2000, 89(6):529-34.

12. Nanda K, McCrory DC, Myers ER, Bastian LA, Hasselblad V, Hickey JD, Matchar DB: Accuracy of the Papanicolaou test in screening for and follow-up of cervical cytologic abnormalities: a systematic review. Ann Intern Med 2000, 132(10):810-9.

13. CDC: Guidelines for preventing opportunistic infections among HIVinfected persons-2002: recommendations of the U.S. Public Health Service and the Infectious Diseases Socciety of America. WWMR Recomm Rep 2002, 5(RR-8):1-52.

14. Solomon D, Davey D, Kurman R, Moriarty A, O'Connor D, Prey M, Raab S, Shueman M, Wilbur D, Wright T Jr, Young N: The 2001 Bethesda System: terminology for reporting results of cervical cytology. JAMA 2002, 287(16):2114-9.

15. Wright TC, Cox JT, Massad LS, Twiggs LB, Wilkinson EJ: 2001 Consensus Guidelines for the management of women with cervical cytological abnormalities. JAMA 2002, 287(16):2120-9.

16. Anderson JR, Paramsothy P, Heilig C, Jamieson DJ, Shah K, Duerr A: Accuracy of Papanicolaou test among HIV-infected women. Clin Infect Dis 2006, 42(4):562-8.

17. Harris TG, Burk RD, Palefsky JM, Massad LS, Bang JY, Anastos K, Minkoff H, Hall CB, Bacon MC, Levine AM, Watts DH, Silverberg MJ, Xue X, Melnick SL, Strickler HD: Incidence of cervical squamous intraepithelial lesions associated with HIV serostatus, CD4 cell counts, and human papillomavirus test results. JAMA 2005, 293(12):1471-6.

18. Agaba PA, Thacher TD, Ekwempu CC, Idoko JA: Cervical dysplasia in Nigerian women infected with HIV. Int J Gynaecol Obstet 2009, 107(2):99-102.

19. Micheletti AM, Dutra Vde F, Murta EF, Paschoini MC, Silva-Vergara ML, Barbosa e Silva G, Adad SJ: Cervicovaginal cytological abnormalities in patients with human immunodeficiency virus infection, in relation to disease stage, CD4 cell count and viral load. Diagn Cytopathol 2009, 37(3):164-9.

20. Franceschi S, Dal Maso L, Suligoi B, Rezza G: Evidence for lack of cervical cancer screening among HIV-positive women in Italy. Eur J Cancer Prev 2006, 15(6):554-6.

21. Sirivongrangson $P$, Bollen $L$, Chaovavanich $A$, Suksripanich $O$, Virapat $P$, Tunthanathip P, Ausavapipit J, Lokpichat S, Siangphoe U, Jirarojwat N, Pobkeeree V, Supawitkul S, Tappero JW, Levine WC: Screening HIV-infected women for cervical cancer in Thailand: findings from a demonstration project. Sex Transm Dis 2007, 34(2):104-7.

22. De Vuyst H, Lillo F, Broutet N, Smith JS: HIV, human papillomavirus, and cervical neoplasia and cancer in the era of highly active antiretroviral therapy. Eur J Cancer Prev 2008, 17(6):545-54.

23. Ahdieh-Grant L, Li R, Levine AM, Massad LS, Strickler HD, Minkoff H, Moxley M, Palefsky J, Sacks H, Burk RD, Gange SJ: Highly active antiretroviral therapy and cervical squamous intraepithelial lesions in human immunodeficiency virus-positive women. Journal of the National Cancer Institute 2004, 96(14):1070-6.

24. Levi JE, Fink MC, Canto CL, Carretiero N, Matsubara R, Linhares I, Das Dores GB, Castelo A, Segurado A, Uip DE, Eluf JJ: Human papillomavirus prevalence, viral load and cervical intraepithelial neoplasia in HIVinfected women. Braz J Infect Dis 2002, 6(3):129-35.

25. Palefsky JM, Minkoff H, Kalish LA, Levine A, Sacks HS, Garcia P, Young M, Melnick S, Miotti P, Burk R: Cervicovaginal human papillomavirus infection in human immunodeficiency virus-1 (HIV)-positive and high-risk HIVnegative women. Journal of the National Cancer Institute 1999, 91(3):226-36.

26. Kitchener H, Nelson L, Adams J, Mesher D, Sasieni P, Cubie H, Moore C, Heard I, Agarossi A, Casolati E, Denny L, Bradbeer C, Lyons F, Beattie G, Niemiec T: Colposcopy is not necessary to assess the risk to the cervix in HIV-positive women: an international cohort study of cervical pathology in HIV-1 positive women. Int J Cancer 2007, 121(11):2484-91.

27. Womack SD, Chirenje ZM, Gaffikin L, Blumenthal PD, McGrath JA, Chipato T, Ngwalle S, Munjoma M, Shah KV: HPV-based cervical cancer screening in a population at high risk for HIV infection. Int J Cancer 2000, 85(2):206-10.

28. Holcomb K, Abulafia O, Matthews RP, Chapman JE, Borges A, Lee YC, Buhl A: The significance of ASCUS cytology in HIV-positive women. Gynecol Oncol 1999, 75(1):118-21.

29. Frazer $\mathrm{IH}$ : Prevention of cervical cancer through papillomavirus vaccination. Nat Rev Immunol 2004, 4(1):46-54.

\section{Pre-publication history}

The pre-publication history for this paper can be accessed here: http://www.biomedcentral.com/1471-2334/11/8/prepub

doi:10.1186/1471-2334-11-8

Cite this article as: Chalermchockcharoenkit et al.: Prevalence and cumulative incidence of abnormal cervical cytology among HIV-infected Thai women: a 5.5-year retrospective cohort study. BMC Infectious Diseases 2011 11:8.

\section{Submit your next manuscript to BioMed Central and take full advantage of:}

- Convenient online submission

- Thorough peer review

- No space constraints or color figure charges

- Immediate publication on acceptance

- Inclusion in PubMed, CAS, Scopus and Google Scholar

- Research which is freely available for redistribution

Submit your manuscript at www.biomedcentral.com/submit
C) Biomed Central 